\title{
SCIENCE IN THE TROPICS
}

$\mathrm{U}^{\mathrm{s}}$ NDER the general title "Science in the Tropics", the annusl seminar held at the Institute of Commonwerlth Studies recently concluded its fourth year of discussions on the impact of the natural sciences in the tropical countries of the Commonwealth. It was agreed that in some fields of research Britain can contribute much in the way of one-time eapital efforts, such as soil and plant-disease surveys and malaria campaigns, but that in the long term, the problem of providing the right incentive to take up scientific studies and to apply them effectively is still largely unsolved. The proportion of $1: 40$ of scientists to technical assistants in one commodity research station was quoted as reflecting the danger of lowering the standard of work that could be done. These stations must of necessity work in isolation from the daily life of the community, although it is the community which must willingly support research and from which the research workers must eventually be provided.

Public relations maintained in a variety of ways, from the inculcation of ideas in early education to frank glamorization and acknowledgment of the work of the scientist, were variously advocated for accelerating the progress of science in tropical countries. The provision of funds for these activities presupposes an awareness by the politician and the administrator of the losses caused by ignorant cultivation, diseases and pests of crops and human beings, and lack of knowledge about their control. The principle of wise investment, either by governments, individuals or co-operatives in scientific research and still more in extension work, involves the denial of present consumption for inassessable future benefits. With alarming increases in population resulting from health campeigns and improved economic systems, many tropical countries will be forced to develop scientific methods capable of producing dramatic increases in food or cash crops. The whole problem of family limitation will have to be faced squarely, especially in India and the Far East.
Scientific studies of diet and nutrition will enable better use to be made of existing crops or to shift the emphasis on to crops of better nutritional value. The education of women in this and other domestic fields was stressed several times during the discussions.

But it was clear that at present the number of research scientists coming forward is hopelessly inadequate to cope with the problems, especially on the continent of Africa, and the only recourse is to invoke massive aid from the older established scientific centres of Europe and America. Such aid is necessarily only forthcoming when the problems have already become sufficiently acute to attract general attention.

Other topics discussed included the important part played by commercial firms in bringing modern applications of science, in the shape of machinery, fertilizers, fungicides and insecticides, to the tropical cultivator. Even in this field the recovery of very large development costs is endangered by commercial competition, and this tends to set back the advance of many scientific applications.

The seminar was under the chairmanship of Dr. W. F. Jepson, of the Imperial College of Science and Technology, London, and the opening speakers were Dr. Herbert Greene, of Rothamsted Experimental Station, on soil studies; Mr. George Ordish, of Imperial Chemical Industries, Ltd., on the economics of tropical research and extension work; Prof. B. S. Platt, of the London School of Hygiene and Tropical Medicine, on nutrition research; Dr. C. G. Johnson, of Rothamsted, on commodity research stations; Mr. V. L. Griffiths, of Oxford, on early education; Prof. G. Macdonald, director of the Ross Institute, on public health; Dr. F. P. Coyne, of Imperial Chemical Industries, Ltd., on the introduction of pesticides into the tropics ; and Dr. J. C. F. Hopkins, director of the Commonwealth Mycological Institute, on the impact of plant diseases.

W. F. JEPSON

\section{THE NATIONAL RESEARCH DEVELOPMENT CORPORATION}

\begin{abstract}
$\mathrm{T}$
HE report and statement of accounts* of the National Research Development Corporation for the year ended June 30, 1957, covers the eighth year of the Corporation's activities and notes an encouraging rising trend in the royalty income. All sixteen electronic digital computers commissioned by the Corporation are in operation and the Pegasus computer has proved a most successful and popular design. A new project under consideration is concerned with construction of computers several hundred times faster than those at present available. A patent pool has been created for electronic digital computers and, as a member, the Corporation has made all its patents which bear on digital computers available through the medium of the pool licence. Eight scholarships, each for three years, have been made available at the University of Manchester for postgraduate training of computer engineers and

- National Research Development Corporation. Report and Statement of Accounts for the year 1st July, 1956, to 30th June, 1957. Pp. 30. (I.ondon: H.M. Stationery Offee, 1958.) 28. net.
\end{abstract}

programmers, and four annual scholarships at the University of Cambridge for postgraduate students taking the diploma course in numerical analysis and automatic computing.

The Packman potato harvester has been further improved so as to reduce crop damage, and the National Institute of Agricultural Engineering completed development work on its small potato harvester. The design of a complete full-scale prototype regenerative mechanical transmission system is well advanced, and extension to cream of a process developed at the National Institute for Research in Dairying whereby freshly pasteurized millk is treated with ultrasonic waves poured into polyethylene bags and quickly frozen promises to solve the serious problem presented by rapid deterioration of cream in transport and storage. A valuable by-product of the liquid gases plant project has been the development of a stabilized high-speed air bearing.

Development projects noted for the first time in the report include work on the production of aldo- 